\title{
Evaluation of selected ultra-trace minerals in commercially available dry dog foods
}

\author{
Hyun-tae Kim' \\ John P Loftus' \\ Jason W Gagné \\ Michael A Rutzke ${ }^{2}$ \\ Raymond P Glahn ${ }^{3}$ \\ Joseph J Wakshlag'
}

'Cornell University College of Veterinary Medicine, Department of Clinical Sciences, Ithaca, NY, USA; ${ }^{2}$ Cornell University, College of Agriculture and Life Sciences, School of Integrative Plant Sciences, Ithaca, NY, USA; ${ }^{3}$ Robert W. Holley Center for Agriculture and Health, Agricultural Research Service, USDA, Ithaca, NY, USA
Correspondence: Joseph J Wakshlag Cornell University College of Veterinary Medicine, Department of Clinical Sciences, Ithaca, NY 14853, USA

$\mathrm{Tel}+\mathrm{I} 6072533060$

Fax + I 6072533788

Email jw37@cornell.edu
This article was published in the following Dove Press journal: Veterinary Medicine: Research and Reports

Purpose: To evaluate the concentrations of chromium, nickel, molybdenum, silica, and aluminum in several commercially available dry dog foods and compare these with current World Health Organization's (WHO) mean human daily dietary intake. Conversion of dietary intake per megacalorie (Mcal) for both dog foods and human average intake was performed based on the National Research Council recommendation of a 2,900 kcal diet for comparative purposes to average intake and potential toxic exposure.

Materials and methods: Forty-nine over-the-counter dry foods formulated for maintenance of healthy dogs yet listed as all life stage foods were analyzed. Concentrations of the ultra-trace minerals were measured via inductively coupled plasma atomic emission and represented per Mcal for comparative purposes as it relates to common intake in dogs in comparison with humans. Results: Chromium, molybdenum, and aluminum concentrations in all of the dog foods were at levels that would be considered above average human daily consumption on a caloric basis. Nickel and silica calculated intakes per Mcal were comparable with human intake patterns, while both trace minerals displayed outliers exceeding at least twofold of the upper range of human daily intake.

Conclusion: Overall, ultra-trace minerals found in dog foods were above the expected average daily intake for humans on a caloric basis. There was no evidence of potential chronic toxic exposure based on presumptive intake extrapolated from WHO published toxic intake concentrations for humans or domestic animals. The large range of silica intake from various foods $(2.96-83.67 \mathrm{mg} / 1,000 \mathrm{kcal})$ may have health implications in dogs prone to silica urolithiasis. Further studies investigating the bioavailability of these ultra-trace minerals and establishing dietary ultra-trace mineral allowance would be ideal; however, based on these findings, consumption of these ultra-trace minerals in over-the-counter dry dog foods appears safe.

Keywords: dog food, ultra-trace minerals, food safety, ICP-AES

\section{Introduction}

Commercial pet food safety is frequently questioned because it is directly related to companion animal health. There have been a number of pet food recalls over the past 10 years, and most pet food recalls were due to microbial contamination, adulteration with toxic or foreign materials, or mixing or formulation error. ${ }^{1-3}$ Such a contamination can be prevented in pet foods with proper quality controls, but certain trace minerals cannot be avoided since many of these trace elements are naturally occurring in commonly used ingredients. When exposed to high concentrations chronically, certain ultra-trace minerals may adversely affect animal health. ${ }^{4-8}$ 
While major minerals and trace minerals in pet foods are regulated by the US National Research Council (NRC) and the Association of American Feed Control Officials (AAFCO), there are no standards, set by regulatory agencies, for monitoring ultra-trace minerals such as chromium, nickel, molybdenum, silica, and aluminum. The primary reason is lack of evidence regarding deficiency across species due to ubiquitous exposure in the environment and foods consumed. Chromium, nickel, molybdenum, and silica are all thought to be involved in specific enzymatic systems and likely have dietary requirements.

Trivalent chromium is involved in the metabolism of energy sources. ${ }^{4}$ On the other hand, hexavalent chromium tends to be toxic causing organ damage and death. Even though plants do not require chromium for their growth and development, chromium bioaccumulation occurs in plants depending on the soil. ${ }^{9}$ Nickel provides catalytic function of some enzymes such as urease, hydrogenases, $\mathrm{CD}$ dehydrogenase, and methyl-coenzyme $\mathrm{M}$ reductase; also, it is naturally derived from typical diets. ${ }^{10}$ In the case of molybdenum, it is utilized for oxygen exchange of oxidase enzymes in higher animals, and appropriate intake comes from animal and plant ingredients containing molybdenum. ${ }^{11,12}$ Silica, the second most abundant element in the earth, is a ubiquitous mineral that is essential for calcification and maturation of bone. It is also involved in collagen synthesis by acting as a cofactor for prolyl hydrase. ${ }^{13}$ On the other hand, aluminum is considered a toxic element with no known physiologic requirement, and it accumulates in the body from food or environmental exposures such as coal mining areas and local incinerator exposures.

There have been some studies regarding trace and ultratrace mineral contamination of commercial pet foods in a few countries including the USA. ${ }^{14-16}$ However, there are no recommended dietary allowances or safe upper limits determined for the ultra-trace minerals described, and neither AAFCO nor NRC provides recommendations for dietary intake of these minerals in dogs. Toxicity of these elements has been examined in some species, yet the relative intake or amounts of these ultra-trace minerals have not been reported in dogs. We hypothesize that the levels of intake based on this cross section of the dry commercial dog food market will show that their consumption is similar to human consumption patterns and should be safe. Therefore, we quantitatively examined the ultra-trace element content of 49 commercial dog foods available in the US market with inductively coupled plasma - atomic emission spectrometry (ICP-AES). These results were then converted to consumption per megacalorie (Mcal) and compared to the typical average chronic consumption established by the World Health Organization (WHO) and assessed against WHO toxic consumption information.

\section{Materials and methods Analyzed foods}

Samples of 49 dry foods formulated for the maintenance of healthy dogs and commonly sold over the counter (i.e., maintenance foods) were obtained in Ithaca, NY (Supplementary material). One food commonly dispensed to healthy dogs at the Cornell University Veterinary Medical Center $(n=1)$ was chosen, and the remaining samples were obtained from a local pet food retailer $(n=12)$, a local grocery store $(n=12)$, or two large national pet food retailers $(n=24)$. All samples were stored at room temperature and analyzed within a week after purchase.

\section{Sample preparation}

A portion of each product was individually placed in a grinder (Cool Grind Blade Grinder, No. 501; Capresso, Closter, NJ, USA) and pulverized. To prevent cross contamination, the grinder was cleaned and vacuumed between samples. Approximately $0.5 \mathrm{~g}$ of each food was weighed (Summit Series SI-603; Denver Instrument, Bohemia, NY, USA) accurate to $0.001 \mathrm{~g}$ and placed in a low thermal expansion borosilicate glass tube. Samples were prepared in triplicate.

\section{Inductively coupled plasma - atomic emission spectrometry}

Mineral analysis was done at the USDA Robert Holley Center for Agriculture and Health, Ithaca, NY. Four milliliters of a 60:40 mixture of a double-distilled $70 \% \mathrm{HNO}_{3}-\mathrm{HClO}_{4}$ combination and $0.25 \mathrm{~mL}$ of yttrium $(40 \mathrm{mg} / \mathrm{L})$ were added to each pulverized sample for ICP-AES as an internal standard to assess matrix interference. Acid-treated samples were incubated overnight at room temperature, then heated to $120^{\circ} \mathrm{C}$ in an aluminum heating block for 2 hours for sample clarification. For samples that failed to clarify, $0.25 \mathrm{~mL}$ of concentrated nitric acid was added for further digestion until the temperature reached $195^{\circ} \mathrm{C}$. After cooling to room temperature $\left(\sim 20^{\circ} \mathrm{C}\left[68^{\circ} \mathrm{F}\right]\right), 20 \mathrm{~mL}$ of deionized water was added, the samples were vortexed, and the solutions were transferred into tubes for analysis via ICP-AES.

Concentrations of chromium, nickel, molybdenum, silica, and aluminum were determined by means of ICP-AES (Thermo Scientific iCAP 6500; Thermo Fisher Scientific, 
Cambridge, UK). In this instrument, a 150-mm lens (Optical transfer device for axially viewed ICP spectrometers; Cornell Research Foundation, Ithaca, NY, USA) was inserted in the base of the ceramic purge tube to reduce matrix interferences. ${ }^{17-19}$ Data output from ICP-AES was expressed as mg/L on the basis of three 10-second integrations. Element concentrations were drift corrected and normalized with the yttrium internal standard. To express these data in micrograms per gram, the following equation was used:

$$
([\mathrm{M} \times 10 \mathrm{~mL}] \mathrm{Y}) / \mathrm{W}
$$

where $\mathrm{M}$ is the mineral of interest in ppm, $\mathrm{Y}$ is the yttrium (internal standard) value, and $\mathrm{W}$ is the weight of the sample in grams. The intra-assay coefficient and intra-assay coefficient of variation were below $12 \%$ and $10 \%$, respectively, for all of the ultra-trace minerals examined.

The mean of triplicate analyses $(\mu \mathrm{g} / \mathrm{g})$ was divided by the energy density ( $\mathrm{kcal} / \mathrm{kg}$ ) of food (on the basis of information obtained from the manufacturer) and then multiplied by 1,000 to express each mineral concentration in $\mathrm{mg} / 1,000 \mathrm{kcal}$.

\section{Normalization of mineral concentration to food caloric content}

All manufacturers were contacted to verify the energy content of metabolizable energy (ME) in marketed food on a kilogram basis. Measured trace element concentrations (mg mineral $/ \mathrm{kg}$ food) were normalized against the calculated food energy density from company data and expressed as $\mathrm{mg} / 1,000 \mathrm{kcal} \mathrm{ME}$ to allow comparisons between products and estimation of expected mineral intake on the basis of manufacturer feeding recommendations. Concentrations of trace metals in each food were subjectively compared to WHO average daily intakes considered safe after conversion to intake per 1,000 kcal ME based on the normal human daily calorie requirement set forth by the $\mathrm{NRC}{ }^{20}$

\section{Statistical analysis}

Data were examined for Gaussian distribution via ShapiroWilk and quantile plots (GraphPad Prism 7; GraphPad Software, La Jolla, CA, USA). Due to a lack of parametric distribution, medians and ranges were reported for all ultra-trace minerals. Box-and-whisker plots were used for descriptive statistics for representation of the data using the 2.5 th and 97.5th percentiles with outliers represented. Data for each mineral were reported as being above or below the common daily intake for humans and percentage of foods that were above the WHO levels for chronic toxic exposure.

\section{Results}

Median and range trace element concentrations per 1,000 kcal in maintenance foods $(n=49)$ for dogs were subjectively compared with available toxicity and daily intake information of each ultra-trace mineral (Figures 1 and 2).

The median concentration of chromium in maintenance foods was $0.47 \mathrm{mg} / 1,000 \mathrm{kcal} \mathrm{ME}$ (range, $0.17-2.05 \mathrm{mg} / 1,000$ kcal ME). In humans, the dietary chromium intake in North America was found to be $60-90 \mu \mathrm{g} /$ day, and the typical range was $50-200 \mu \mathrm{g} /$ day. ${ }^{21}$ The typical daily intakes can be converted to $0.017-0.069 \mathrm{mg} / 1,000 \mathrm{kcal} \mathrm{ME}$ using the estimated caloric requirements of adults $\left(2,900 \mathrm{kcal}\right.$ per day). ${ }^{20}$ Based on this information, the average daily intake of the common dog eating over-the-counter commercial dry dog food would be $\sim 30$-fold higher than the maximum typical intake in humans.

The median concentration of nickel in maintenance foods was $0.26 \mathrm{mg} / 1,000 \mathrm{kcal} \mathrm{ME}$ (range, $0.1-0.87 \mathrm{mg} / 1,000 \mathrm{kcal}$ $\mathrm{ME})$. A human average daily intake is $\sim 200-300 \mu \mathrm{g} / \mathrm{day}^{22}$ This daily intake can be converted to $0.069-0.103 \mathrm{mg} / 1,000$ kcal ME using the estimated calorie needs of adults. All of the dog foods exceeded the daily human average nickel intake per Mcal. The dog food containing the highest nickel concentration had $0.87 \mathrm{mg} / 1,000 \mathrm{kcal} \mathrm{ME}$ and would be

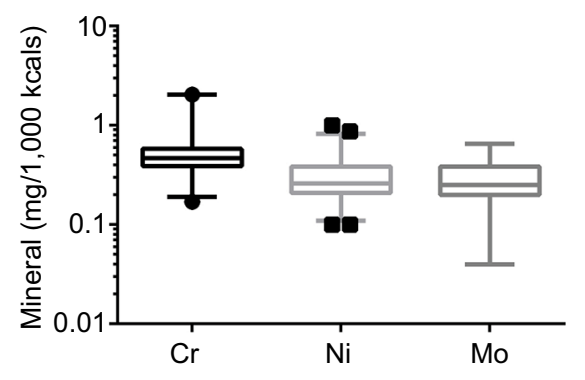

Figure I Box-and-whisker plots of chromium, nickel, and molybdenum concentrations found in 49 dry dog foods.

Notes: Boxes represent the 25th and 75th percentiles, and whiskers represent the 2.5 th and 97.5 th percentiles. Solid lines within boxes represent the median values, respectively. Black dots indicate outliers $(<2.5 \%$ or $>97.5 \%)$.

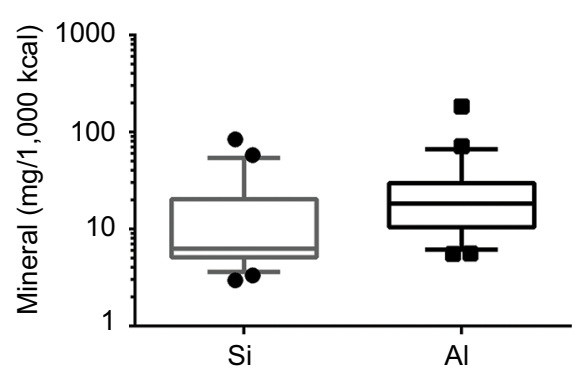

Figure 2 Box-and-whisker plots of silica and aluminum concentrations found in 49 dry dog foods.

Notes: Boxes represent the 25 th and 75 th percentiles, and whiskers represent the 2.5 th and 97.5th percentiles. Solid lines within boxes represent the median values, respectively. Black dots indicate outliers $(<2.5 \%$ or $>97.5 \%)$. 
considered eightfold higher than the average daily intake per Mcal in a typical person, while the lowest amount found in dog foods is similar to the average human intake per Mcal.

The median concentration of molybdenum in maintenance foods was $0.25 \mathrm{mg} / 1,000 \mathrm{kcal} \mathrm{ME}$ (range, 0.04-0.65 $\mathrm{mg} / 1,000 \mathrm{kcal} \mathrm{ME}$ ). Humans have been recommended a daily allowance of $45 \mu \mathrm{g}$ molybdenum per day and estimated daily molybdenum intake of Northeastern United States population was $0.074-0.126 \mathrm{mg} /$ day. ${ }^{23}$ The daily intake of the Northeastern United States can be converted to 0.026-0.043 mg/1,000 kcal ME using the estimated calorie needs of adults $(2,900 \mathrm{kcal} / \mathrm{day})$. The highest amount of molybdenum contained in dog foods was $0.65 \mathrm{mg} / 1,000$ kcal ME exceeding 15-fold of the highest range for human intake, while all the dog foods analyzed in this study were above the estimated intake.

The median concentration of silica in maintenance foods was $6.28 \mathrm{mg} / 1,000 \mathrm{kcal} \mathrm{ME}$ (range, 2.96-83.67 mg/1,000 kcal ME). Data on the Western United States population show a silicon intake of $20-50 \mathrm{mg} /$ day, respectively, and food is the main source of silica acquisition. ${ }^{24}$ The daily silica intake can be converted to $17.2 \mathrm{mg} / 1,000 \mathrm{kcal} \mathrm{ME}$ using the estimated calorie intake of adult humans. Only nine dog foods were above the highest human daily silica intake per Mcal.

The median concentration of aluminum in maintenance foods was $18.22 \mathrm{mg} / 1,000 \mathrm{kcal} \mathrm{ME}$ (range, 5.55-183.23 $\mathrm{mg} / 1,000 \mathrm{kcal} \mathrm{ME})$. The US Food and Drug Administration estimates $\sim 2-14 \mathrm{mg} /$ day. ${ }^{25,26}$ The range of daily human aluminum intake can be converted to $0.69-4.8 \mathrm{mg} / 1,000 \mathrm{kcal} \mathrm{ME}$ using the estimated calorie needs of adults. Most (46/49) of the dog foods were above the upper range of human intake per Mcal, and the pet food with the highest aluminum content was 38-fold higher than the upper range of human daily intake.

\section{Discussion}

The findings of our study suggest that the exposure of ultratrace minerals in dogs may be higher than in humans, suggesting that there is adequate exposure to these ultra-trace minerals in the diet with no obvious lack of intake using commercial dog foods. More importantly, there is no evidence that the ultra-trace mineral consumption would be deleterious based on known toxic levels of the ultra-trace minerals analyzed in this study. The minerals of greatest concern for toxic exposure would be chromium, nickel, and aluminum; however, there is very little known about the absorption kinetics, matrix, or other mineral interferences on the absorption kinetics of these minerals in dogs. This lack of knowledge allows for very little extrapolation of the results in this study to potential in vivo exposure. Particularly, the valence forms of certain trace minerals are more toxic than others (i.e., hexavalent vs. trivalent chromium), and the exact forms of these minerals in a dog food matrix are unknown.

Chromium is an essential trace element that has a biologic role in the body system functioning as a cofactor for insulin. ${ }^{27-29}$ It is also related to a number of enzymes involved in glucose, amino acid, and lipid metabolism, and is considered an essential nutrient. ${ }^{30,31}$ Adequate intake of chromium has been set at 20-35 $\mu \mathrm{g}$ /day in human adults, and its deficiency causes various clinical symptoms such as lean body mass reduction, body fat percentage elevation, glucosuria, insulin resistance, impaired fertility, and cardiovascular disease. ${ }^{4,20,32,33}$ A study using $20-60 \mu \mathrm{g} / \mathrm{kg} /$ day oral chromium in diabetic dogs did not find any beneficial effects on glucose control and no detriment to the doses used in this short-term exposure. ${ }^{34}$ The assumptions from this study were that the dog food being used had adequate chromium concentrations since purified diets were not utilized in this study. Chromium concentrations (0.17-2.05 mg/1,000 kcal ME) of the dog foods analyzed encompass the adequate human intake with an average $15 \mathrm{~kg}$ dog achieving higher intakes than the recommended intake for humans. Conversely, excess chromium is related to gastroenteritis, dermatitis, kidney insufficiency, and liver damage, and a chromium dose of $10-20 \mathrm{mg} / \mathrm{kg}$ body weight has been associated with tubular necrosis, primarily as the hexavalent form. ${ }^{4,32}$ The form observed in food matrices is usually the less toxic trivalent form for which the NRC's established maximum tolerable limit of consumption is 3,000 $\mathrm{mg} / \mathrm{kg}$, which is a thousand fold higher than the amounts any dog would consume from dog foods. ${ }^{35}$

Nickel is considered as an essential nutrient as its deficiency causes clinical signs related to poor development and reproduction. ${ }^{36}$ Other signs of nickel deficiency reported are reduction of serum glucose concentration and changes in absorption and deposition of other major minerals such as calcium, iron, and zinc in the body. Nickel ingestion cannot be avoided due to the fact that soil generally contains 3-1,000 mg nickel per $1 \mathrm{~kg}$ of soil, making deficiency improbable with normal food consumption. Excessive consumption of nickel results in toxic effects associated with gastrointestinal irritation (nausea, abdominal pain, diarrhea, and vomiting) and shortness of breath in humans and reproductive failure and growth inhibition in rats. ${ }^{5,37-39}$ The Food and Nutrition Board proposed the upper limits of nickel intake for children at $0.2-0.6 \mathrm{mg} /$ day depending on their age and for adults at $1.0 \mathrm{mg} /$ day as proposed average daily intake. ${ }^{33}$ In addition, $5 \mathrm{mg} / \mathrm{kg} /$ day of nickel was found to show no adverse effects 
in rats. ${ }^{10}$ Based on our results, a typical $15 \mathrm{~kg}$ dog would ingest between 0.1 and $0.87 \mathrm{mg} / \mathrm{day}$, which is below the proposed upper limits for adult humans, and within the range of children. Since most (90\%) of the ingested nickel is not absorbed, and most of the absorbed nickel is secreted in urine, toxicity through bioaccumulation is difficult to achieve with normal feed ingredients. ${ }^{40}$ Depending on the different forms of nickel, it has a broad range of $\mathrm{LD}_{50}(310-11,000 \mathrm{mg} / \mathrm{kg}$ body weight). The NRC's maximum tolerable levels in feed have been established at $100 \mathrm{mg} / \mathrm{kg}$ of diet, which would average $\sim 25 \mathrm{mg} / 1,000 \mathrm{kcal}$ based on a $4,000 \mathrm{kcal} / \mathrm{kg}$ average $\operatorname{dog}$ food; thus, the lowest level of acute oral $\mathrm{LD}_{50}$ for toxicity cannot be reached with dog foods containing the highest nickel content. ${ }^{41,42}$

Molybdenum is considered as an essential nutrient for animals for enzymatic reactions, but its deficiency in dogs has not been reported. In other animals, molybdenum insufficiency resulted in reduced quality of eggs and feathers in poultry and reproductive problems in goats. ${ }^{43}$ All of the dog foods in this study contained molybdenum above the lowest level of human daily intake making deficiency unlikely. Conversely, the toxic adverse effects of molybdenum in ruminant species including anemia, severe diarrhea, profuse salivation, mucoid feces, renal tubule necrosis, and death are related to copper deficiency as molybdenum is a factor that hinders copper absorption and utilization. ${ }^{6}$ The commercial food with the highest concentration of molybdenum was $0.65 \mathrm{mg} / 1,000 \mathrm{kcal}$ $\mathrm{ME}$, which is 25 -fold higher than the lowest concentration for human daily intake per Mcal. In humans, $90 \mathrm{mg}$ molybdenum per kilogram body weight caused a $22 \%$ reduction in body weight of subjects, but this dose is not achievable through consumption of commercial dog foods made with typical ingredients ${ }^{44}$ In addition, dog foods are fortified with copper at minimally $1.7 \mathrm{mg} / 1,000 \mathrm{kcal}$ to ensure that the interference of molybdenum is minimal, and the NRC's lowest observed adverse effect limit is $\sim 7 \mathrm{mg} / \mathrm{kg}$, which is far higher than the amount consumed by dogs using commercial dog foods of even the highest concentration of $0.65 \mathrm{mg} / \mathrm{Mcal}$ which is minimally a $3: 1$ ratio of copper to molybdenum. ${ }^{45}$

Silica is an essential nutrient that is ubiquitous in the environment as it is a major constituent in soil, but its metabolic functions were unclear until recently. Genes related to a group of silica transport proteins have been identified in lower organisms, but not in higher vertebrates. ${ }^{46}$ Silica is involved in bone growth and connective tissue development, and its deficiency in chickens and rats causes bone, joints, skin, feathers, and hair abnormalities. ${ }^{13}$ Although presumed essential, adequate intake and recommended dietary allowance of silica are not set for humans or dogs as its abundance in foods and the environment prevents any deficiency syndromes. Dietary silica intake of Western populations is $\sim 20-50 \mathrm{mg}$ silicon/day and about four times higher in Indian and Chinese populations that mainly consume plant-based diets. Excessive dietary intake of silica does not cause metabolic problems unless the subject is prone to silica urolithiasis. Chronic consumption of antacids composed of magnesium trisilicate results in the development of silica urolithiasis in humans. ${ }^{47} \mathrm{In}$ dogs, consumption of pet foods containing corn gluten, rice hulls, or soybean hulls is associated with an increased risk of silica stone formation. Among the pet foods analyzed in this study, nine diets were above human daily silica intake, but only one diet included rice hulls. ${ }^{48}$ A typical $15 \mathrm{~kg}$ dog would ingest between 2.96 and $83.67 \mathrm{mg}$ silica per day according to our data, and this will be well below human daily silica intake when compared with the Indian or Chinese populations. In the most recent canine urolithiasis survey involving 75,647 urinary stones, the prevalence of silica stone was found to be $0.7 \%$ of all stones evaluated. ${ }^{49}$ The breeds that are predisposed to form silica urolithiasis such as German Shepherds, Golden Retrievers, Shih Tzus, Black Labrador Retrievers, Rottweilers, Miniature Schnauzers, and Cocker Spaniels should avoid pet foods higher in silica, which can be tested in many commercial laboratories. ${ }^{8}$

One limitation of our study is the use of glass tubes for the preparation of our samples which, if defective, have the potential to leach silica into the medium for analysis. Based on the fact that our concentrations of silica are lower or similar to what is typically found in common foods and the intake per Mcal was lower than average human consumption contamination of our samples with silica was unlikely. However, we cannot rule out that the handful of elevated outlier concentrations was not from integrity problems with the boro-silicate glass tubes resulting in higher than expected concentrations. These samples were run in triplicate making contamination unlikely since the triplicate samples showed similar concentrations. Contamination of other trace minerals like nickel can occur due to human handling of the samples from saliva or sweat. These contamination problems are not likely to be of concern since dog foods are not handled from the point of ingredient preparation to extrusion or bagging; however, air contamination is possible in highly polluted areas. All dog food bags were opened, and samples were handled with latex gloves during preparation to minimize these potential confounders. Additionally, our laboratory handles many samples from a variety of commercial and agricultural sources for mineral analysis, and matrices can 
affect the extraction of minerals. The methods utilized have been shown to be adequate for all samples tested to date from extruded food items, and the yttrium standard curve utilized showed over $90 \%$ recovery across all samples, suggesting that this unique matrix of dog food was unlikely to confound the results presented. ${ }^{17-19}$

Aluminum is the only nonessential trace mineral with no biological function in dogs that was examined, while it is known to have health implications that are inevitable due to its pollution in the environment. Aluminum neurotoxicity has been reported in dogs. ${ }^{50-52}$ Clinical signs exhibited by the degenerative disease are identical to human's case, where cognitive abilities are lost including memory and recognition as well as other signs including dermatitis, nasal discharge, and discoloration of the nasal planum. ${ }^{7,53}$ The $\mathrm{LD}_{50}$ range of aluminum substances in laboratory animals was $162-980 \mathrm{mg} / \mathrm{kg} .{ }^{54-56}$ The $\mathrm{LD}_{50}$ would not be achievable even at the highest intake possible with exposure $<10 \mathrm{mg} / \mathrm{kg}$. Doses of aluminum hydroxide often utilized for phosphorus binding in kidney disease are $10-30 \mathrm{mg} /$ $\mathrm{kg}$ /day of elemental aluminum medically, and the dose is considered safe while having the effect of sequestering dietary phosphorus. These doses are excessive, and dog food consumption results in far lower intakes than those shown to induce clinical signs as the NRC's maximum tolerable intake is $\sim 1,000 \mathrm{mg} / \mathrm{kg}$ daily. ${ }^{57}$

The higher exposure to ultra-trace minerals in dogs may be attributed to human foods having more processed (e.g., corn starch, white rice, and bleached flour) ingredients than dog foods. Often, more natural ingredients without refinement are incorporated to produce pet foods leading to potentially higher exposure to ultra-trace minerals. In addition, the larger surface area-to-volume ratio (higher basal metabolic rate) of dogs compared to humans allows for a slightly higher caloric consumption per kilogram of metabolic body weight. This higher kilocalorie consumption per kilogram when compared with humans can lead to higher relative intake of the ultra-trace minerals.

\section{Conclusion}

Our findings of relatively high ultra-trace mineral concentrations in pet foods which were compared with ultra-trace mineral ranges of total dietary intakes of humans or other species suggest slightly higher exposure in dogs than in humans. The exact reasons for this finding are unclear but may have to do with the slightly higher metabolic demands of dogs than humans who require fewer calories per kilogram body weight and/or the modest differences in common food ingredients used in the dog food industry compared to foods consumed by humans. Further study investigating the bioavailability of each mineral and establishing dietary ultra-trace mineral allowance would be ideal for dogs consuming typical dry commercial dog foods.

\section{Author contributions}

JJW, HK, JWG, and RPG were involved in the study design, data analysis, interpretation, manuscript preparation, and review. MR was involved in the laboratory analysis, manuscript preparation and editing. JL was involved in data interpretation, manuscript preparation, and review. All authors contributed toward data analysis, drafting and revising the paper and agree to be accountable for all aspects of the work.

\section{Disclosure}

The authors report no conflicts of interest in this work.

\section{References}

1. Eirmann L, Cowell C, Thompson L. Pet food safety: the roles of government, manufacturers, and veterinarians. Compend Contin Educ Vet. 2012;34(1):E1-E3.

2. DogFoodAdvisor [https://www.dogfoodadvisor.com/]. Dog Food Recalls; [updated December 22, 2017; cited December 22, 2017]. Available from: https://www.dogfoodadvisor.com/dog-food-recalls/. Accessed January 2, 2018.

3. Dobson RLM, Motlagh S, Quijano M, et al. Identification and characterization of toxicity of contaminants in pet food leading to an outbreak of renal toxicity in cats and dogs. Toxicol Sci. 2008;106(1):251-262.

4. Thompson LJ. Chromium, iodine and phosphorus. In: Gupta RC, editor. Veterinary Toxicology. Amsterdam, the Netherlands: Elsevier; 2012:508-509.

5. Ambrose AM, Larson PS, Borzelleca JF, Hennigar GR. Long term toxicologic assessment of nickel in rats and dogs. J Food Sci Technol. 1976;13:181-187.

6. Hall JO. Molybdenum. In: Gupta RC, editor. Veterinary Toxicology. Amsterdam, the Netherlands: Elsevier; 2012:544-548.

7. Gupta RC. Aluminum. In: Gupta RC, editor. Veterinary Toxicology. Amsterdam, the Netherlands: Elsevier; 2012:493-498.

8. Aldrich J, Ling GV, Ruby AL, Johnson DL, Franti CE. Silica-containing urinary calculi in dogs (1981-1993). J Vet Intern Med. 1997;11(5): 288-295.

9. Eckhert CD. Trace elements: chromium. In: Ross AC, Caballero B, Cousins RJ, Tucker KL, Ziegler TR, editors. Modern Nutrition in Health and Disease. 11th ed. Philadelphia, PA: Lippincott Williams and Wilkins, Wolters Kluwer Health; 2014:251-252.

10. Eckhert CD. Trace elements: nickel. In: Ross AC, Caballero B, Cousins RJ, Tucker KL, Ziegler TR, editors. Modern Nutrition in Health and Disease. 11th ed. Philadelphia, PA: Lippincott Williams and Wilkins, Wolters Kluwer Health; 2014:254.

11. Johnson JL, Hainline B, Rajagopalan KV. Characterization of the molybdenum cofactor of sulfite oxidase, xanthine oxidase, and nitrate reductase. J Biol Chem. 1980;255(5):1783-1786.

12. Rajagopalan KV. Molybdenum: an essential trace element in human nutrition. Аnnu Rev Nutr. 1988;8(1):401-427.

13. Carlisle EM. Silicon as an essential trace element in animal nutrition. Ciba Found Symp. 2007;121:123-139.

14. Abd-Elhakim YM, El Sharkawy NI, Moustafa GG. An investigation of selected chemical contaminants in commercial pet foods in Egypt. J Vet Diagn Invest. 2016;28(1):70-75. 
15. Duran A, Tuzen M, Soylak M. Trace element concentrations of some pet foods commercially available in Turkey. Food Chem Toxicol. 2010;48(10):2833-2837.

16. Mumma RO, Rashid KA, Shane BS, et al. Toxic and protective constituents in pet foods. Am JVet Res. 1986;47(7):1633-1637.

17. Rutzke MA. An optical interface was developed to reduce the matrix effects observed in an axially viewed ICP-OES (abstr). In: International Conference in Environment Systems Proceedings. Pittcon 1999;038.

18. Rutzke MA. An optical interface that can optically section an axially viewed plasma (abstr). In: Proceedings 24th Annu Conf Fed Anal Chem Spectros Soc. 1997;664.

19. Rutzke MA. An optical transfer interface system for an axially viewed plasma improves analysis of biological samples. $\mathrm{PhD}$ dissertation. Ithaca, NY: Cornell University; 2002.

20. National Research Council. Recommended Dietary Allowances. 10th ed. Washington, DC: National Academies Press; 1989.

21. Basu, D, Blackburn K, Harris B, Neal MW, Stoss FW. Health Assessment Document for Chromium, EPA-600/8-83-014F. Research Triangle Park, NC: U.S. Environmental Protection Agency; 1984.

22. World Health Organization Regional Publications, Air Quality Guidelines for Europe. 2nd ed. Copenhagen Denmark: World Health Organization; 2000.

23. Barceloux DG. Molybdenum. JToxicol Clin Toxicol. 1999;37(2):231-237.

24. Pennington JAT. Silicon in foods and diets. Food Addit Contam. 1991;8(1):97-118.

25. Pennington JA. Aluminium content of foods and diets. Food Addit Contam. 1987;5(2):161-232.

26. Pennington JA, Schoen SA. Estimates of dietary exposure to aluminium. Food Addit Contam. 12(1):119-128.

27. Anderson RA. Chromium, glucose tolerance, and diabetes. Biol Trace Elem Res. 1992;32(1-3):19-24.

28. Anderson RA, Polansky MM, Bryden NA, Roginski EE, Mertz W, Glinsmann W. Chromium supplementation of human subjects: effects on glucose, insulin, and lipid variables. Metabolism. 1983;32(9):894-899.

29. Jeejeebhoy KN, Chu RC, Marliss EB, Greenberg GR, Bruce-Robertson A. Chromium deficiency, glucose intolerance, and neuropathy reversed by chromium supplementation, in a patient receiving long term total parenteral nutrition. Am J Clin Nutr. 1977;30(4):531-538.

30. Ducros V. Chromium metabolism - a literature review. Biol Trace Elem Res. 1992;32(1-3):65-77.

31. Riales R, Albrink MJ. Effect of chromium chloride supplementation on glucose tolerance and serum lipids including high-density lipoprotein of adult men. Am J Clin Nutr. 1981;(34):2670-2678.

32. World Health Organization Regional Publications. Chromium. In: Air Quality Guidelines for Europe. 2nd ed. Copenhagen Denmark: World Health Organization; 2000:139-142.

33. Institute of Medicine (US) Panel on Micronutrients. Dietary Reference Intakes for Vitamin A, Vitamin K, Arsenic, Boron, Chromium, Copper, Iodine, Iron, Manganese, Molybdenum, Nickel, Silicon, Vanadium, and Zinc. Washington, DC: National Academy Press; 2001.

34. Schachter S, Nelson RW, Kirk CA. Oral chromium picolinate and control of glycemia in insulin-treated diabetic dogs. J Vet Intern Med. 2009;15(4):379-384.

35. Mineral Tolerance of Animals, Ch.11 Chromium. Washington, DC: National Academy Press; 2005;115-123.

36. Nielsen FH. Ultratrace minerals. In: Shils ME, Olson JA, Shike M et al, editors. Modern Nutrition in Health and Disease. Philadelphia, PA: Lea and Febiger; 1998:283-303.
37. Sunderman FW, Dingle B, Hopfer SM, Swift T. Acute nickel toxicity in electroplating workers who accidently ingested a solution of nickel sulfate and nickel chloride. Am J Ind Med. 1988;14(3):257-266.

38. Smith MK, George EL, Stober JA, Feng HA, Kimmel GL. Perinatal toxicity associated with nickel chloride exposure. Environ Res. 1993;61(2):200-211.

39. Laskey JW, Phelps PV. Effect of cadmium and other metal cations on in vitro Leydig cell testosterone production. Toxicol Appl Pharmacol. 1991;108(2):296-306

40. World Health Organization Regional Publications. Nickel. In: Air Quality Guidelines for Europe. 2nd ed. Copenhagen Denmark: World Health Organization; 2000:162-165.

41. Henderson RG, Durando J, Oller AR, Merkel DJ, Marone PA, Bates HK. Acute oral toxicity of nickel compounds. Regul Toxicol Pharmacol. 2012;62(3):425-432.

42. Mineral Tolerance of Animals, Ch.22 Nickel. Washington, DC: National Academy Press; 2005;276-290.

43. National Research Council. 7. Minerals: molybdenum. In: Nutrient Requirements of Dogs and Cats (2006). Washington, DC: National Academies Press; 2006:185.

44. Agency for Toxic Substances and Disease Registry. Toxicological Profile for Molybdenum: Draft for Public Comment. Atlanta, GA; 2017.

45. Mineral Tolerance of Animals, Ch: Molybdenum. Washington, DC: National Academy Press; 2005;262-275.

46. Wolman AA, Rice DW, Winn HE, Lawton WS. A gene family of silicon transporters. Nature. 1997;385:688-689.

47. Haddad FS, Kouyoumdjian A. Silica stones in humans. Urol Int. 1986;41(1):70-76.

48. Osborne CA, Lulich JP, Ulrich LK. Canine silica urolithiasis: causes, detection, treatment and prevention. In: Hand MS, Thatcher CD, Remillard RL, Roudebush P, editors. Small Animal Clinical Nutrition. 5th ed. Topeka, Kansas: Mark Morris; 2010:915-920.

49. Houston DM, Weese HE, Vanstone NP, Moore AEP, Weese JS. Analysis of canine urolith submissions to the Canadian Veterinary Urolith Centre, 1998-2014. Can Vet J. 2017;58(1):45-50.

50. Behera C, Krishna K, Bhardwaj DN, Rautji R, Kumar A. A case of accidental fatal aluminum phosphide poisoning involving humans and dogs. J Forensic Sci. 2015;60(3):818-821.

51. Segev G, Bandt C, Francey T, Cowgill LD. Aluminum toxicity following administration of aluminum-based phosphate binders in 2 dogs with renal failure. J Vet Intern Med. 2008;22(6):1432-1435.

52. Alfrey AC, Hegg A, Craswell P. Metabolism and toxicity of aluminum in renal failure. Am J Clin Nutr. 1980;33(7):1509-1516.

53. Pettersen JC, Hackett DS, Zwicker GM, Sprague GL. Twenty-six week toxicity study with $\mathrm{KASAL}^{\circledR}$ (basic sodium aluminum phosphate) in beagle dogs. Environ Geochem Health. 1990;12(1-2):121-123.

54. Ondreička R, Ginter E, Kortus J. Chronic toxicity of aluminium in rats and mice and its effects on phosphorous metabolism. Br J Ind Med. 1966;23(4):305-312.

55. Llobet JM, Domingo JL, Gomez M, Tomas JM, Corbella J. Acute toxicity studies of aluminum compounds - antidotal efficacy of several chelating agents. Pharmacol Toxicol. 1987;60:280-283.

56. Yokel RA, McNamare PJ. Aluminum bioavailability and disposition in adult and immature rabbits. Toxicol Appl Pharmacol. 1985;77(2):344-352.

57. Mineral Tolerance of Animals, Ch.3 Aluminium. Washington, DC: National Academy Press; 2005; 15-23. 


\section{Supplementary material}

The list below represents the all life stage dog foods analyzed in this study:

a. Purina One Smart Blend Chicken and Rice, Nestlé Purina Petcare Co, St Louis, MO, USA.

b. Pedigree Adult Small Breed, Mars Petcare US, Brentwood, TN, USA.

c. Canidae All Life Stages, Canidae Corp, San Luis Obispo, CA, USA.

d. Prescription diet g/d Canine, Hill's Pet Nutrition Inc., Topeka, KS, USA.

e. Pedigree Puppy Complete Nutrition, Mars Petcare US, Brentwood, TN, USA.

f. Purina Beneful Original Adult, Nestlé Purina Petcare Co, St Louis, MO, USA

g. 4Health Chicken and Rice, Tractor Supply Co, Brentwood, TN, USA.

h. Timberwolf Dakota Bison Formula, Iron Pyramid LLC, Windmere, FL, USA.

i. Iams Lamb and Rice, Procter \& Gamble Pet Care, Cincinnati, $\mathrm{OH}, \mathrm{USA}$.

j. Dad's Economets Lamb and Rice Meal, DAD'S Pet Care, Meadville, PA, USA.

k. Kibbles 'n Bits Original Savory Beef \& Chicken Flavor, Del Monte Corp, San Francisco, CA, USA.

1. Purina ProPlan Performance, Nestlé Purina Petcare Co, St Louis, MO, USA.

m. Blue Buffalo Natural Chicken and Brown Rice Adult, Blue Buffalo Co Ltd, Wilton, CT, USA.

n. Taste of the Wild High Prairie Canine Formula, Taste of the Wild Pet Food, Meta, MO, USA.

o. Authority Adult Minichunk Real Chicken Adult, Authority Pet Food Co, Phoenix, AZ, USA.

p. Iams Small Bites Adult over 1 year, Procter \& Gamble Pet Care, Cincinnati, OH, USA.

q. Nutro Natural Choice Lamb and Rice Formula Adult, Nutro Product Inc, Franklin, TN, USA.

r. Innova Large Breed Adult Dry Dog Food, Natura Pet Products, Fremont, NV, USA.

s. Eukanuba Adult Maintenance, Procter \& Gamble Pet Care, Cincinnati, OH, USA.

t. Big Red Nuggets dog food, Pro Pet LLC, St Marys, OH, USA.

u. Biljac Adult Select Formula, Kelly Foods Corp, Berlin, MD, USA. v. Hill's Science Diet Adult, Hill's Pet Nutrition Inc., Topeka, KS, USA.

w. Kibbles and Bits Homestyle Adult, Del Monte Corp, San Francisco, CA, USA.

x. Country Natural for Puppies, Grandma Mae's Country Naturals LLC, New York, NY, USA.

y. Wegmans Bruiser, Wegmans Food Markets Inc, Rochester, NY, USA.

z. Purina Puppy Chow large breed, Nestlé Purina Petcare Co, St Louis, MO, USA.

aa. Abady Classic Formula for Maintenance \& Stress, The Robert Abady Dog Food Co, Poughkeepsie, NY, USA.

bb. Solid Gold Hund-n-Flocken, Solid Gold Health Products for Pets Inc., El Cajon, CA, USA.

cc. Newman's Own Organics Adult Dog Formula, Newman's Own Organics Inc., Aptos, CA, USA.

dd. Evo Small Bites Red Meat Formula, Natura Pet Products, Fremont, NV, USA.

ee. Merrick Turducken, Merrick PetCare Inc., Amarillo, TX, USA.

ff. Dick Van Patten's Natural Balance Venison and Sweet Potato and Venison, Dick Van Patten's Natural Balance Pet Foods Inc., Pacoima, CA, USA.

gg. Ol' Roy Complete Nutrition, Wal-Mart Stores Inc., Bentonville, AR, USA.

hh. Rachel Ray Nutrish with Beef and Brown Rice, Ainsworth Pet Nutrition Inc., Meadville, PA, USA.

ii. Eagle Pack Original Pork Meal and Chicken Meal Formula, WellPet LLC, Tewksbury, MA, USA.

jj. Harmony Farms Chicken and Brown Rice Recipe, Sierra Pet Products LLC, Wilton, CT, USA.

kk. Simply Nourish Adult Dog Food Chicken and Brown Rice Recipe, Simply Nourish Pet Food Co, Phoenix, AZ, USA.

11. Royal Canin Medium Adult 25, Royal Canin USA Inc., St Charles, MO, USA.

mm. Royal Canin Energy 4800, Royal Canin USA Inc., St Charles, MO, USA.

nn. Annamaet Encore, Annamaet Petfoods, Sellersville, PA, USA.

oo. Annamaet Salcha, Annamaet Petfoods, Sellersville, PA, USA.

pp. Annamaet Manitok, Annamaet Petfoods, Sellersville, PA, USA.

qq. Annamaet Aqualuk, Annamaet Petfoods, Sellersville, PA, USA. 
rr. Wellness Complete Health, WellPet LLC, Tewksbury, MA, USA.

ss. Orijen Fish, Champion Pet Foods LP, Edmonton, Alberta, Canada.

tt. Acana Pacifica, Champion Pet Foods LP, Edmonton, Alberta, Canada. uu. Iams ${ }^{\circledR}$ ProActive Health ${ }^{\text {TM }}$ Smart Puppy Original, Procter \& Gamble Pet Care, Cincinnati, OH, USA.

vv. Purina Puppy Chow, Nestlé Purina Petcare Co, St Louis, MO, USA.

ww. Exclusive Chicken and Rice Adult Formula, PMI Nutrition, St Louis, MO, USA. 